\title{
Patrimônio Geológico do Litoral da Região Metropolitana de Maceió - RMM, Estado de Alagoas, Nordeste do Brasil
}

\author{
Geological Heritage of the Coastline of the Metropolitan Region of Maceió - RMM, \\ State of Alagoas, Northeast Brazil
}

\author{
FERREIRA ${ }^{1}$, B.; SILVA², T. C. L.; SOARES ${ }^{3}$, M. A.; SANTOS JÚNIOR ${ }^{4}$, J. F. \\ brunge2005@gmail.com
}

\begin{abstract}
Resumo
Este estudo apresenta e discute a geodiversidade costeira da Região Metropolitana de Maceió - RMM, utilizando como metodologia duas etapas distintas e complementares, inventário e avaliação quantitativa dos geossítios. Para isso, 20 áreas amostrais foram escolhidas como representativas da geodiversidade local. Com esses dados, foi possível classificar essas áreas de acordo com seu valor científico e riscos de degradação, apontando 6 tipos genéticosfuncionais. Os geossítios analisados estão estruturados em grupos morfológicos muito variados, cordões arenosos, terraços marinhos, manguezais e áreas de transição. Das áreas mapeadas, 55\% possuem valor científico médio a alto, relacionado a áreas com boa conservação, representando os melhores exemplos regionais de suas características geoambientais. Com relação ao risco de degradação, cerca de $65 \%$ dos geossítios apresentam risco médio a alto de degradação, intimamente relacionado à densidade populacional, sem proteção legal efetiva. A aplicação da metodologia permitiu a obtenção de resultados promissores, possibilitando a descrição e avaliação detalhada dos geossítios. No entanto, dada a diversidade de elementos observados, a área demanda novos estudos, com inserções de novos locais e descrições mais aprofundadas, tendo em vista o desenvolvimento de novas etapas de estudo da geodiversidade mapeada.
\end{abstract}

Palavras-chave: Geodiversidade, Patrimônio Natural, Geoconservação.

\begin{abstract}
This study presents and discusses the coastal geodiversity of the Metropolitan Region of Maceió - RMM, using as methodology two distinct and complementary stages, inventory and quantitative evaluation of geosites. For this, 20 sample areas were chosen as representative of the local geodiversity. With these data, it was possible to classify these areas according to their scientific value and degradation risks, pointing out 6 genetic-functional types. The analyzed geosites are structured on very diverse morphological goups, sandy strands, marine terraces, mangroves end transitional areas. Of the mapped areas, 55\% have medium to high scientific value, related to areas with good conservation, representing the best regional examples of their geoenvironmental features. Regarding the risk of degradation, about $65 \%$ of geosites present medium to high risk of degradation, closely related to population densities, without effective legal protection. The application of the methodology allowed the acquisition of promising results, enabling the description and detailed evaluation of the geosites. However, given the diversity of elements observed, the area demands further studies, with insertions of new locations and deeper descriptions, in view of the development of new stages of study of mapped geodiversity.
\end{abstract}

Keywords: Geodiversity, Nature Heritage, Geoconservation.

\section{INTRODUÇÃO}

Os sistemas naturais deram origem a um complexo mosaico de cenários compostos por elementos físicos e biológicos, irregularmente distribuídos sobre o Território Brasileiro, essas

\footnotetext{
${ }^{1}$ Bruno Ferreira, Instituto de Geografia, Desenvolvimento e Meio Ambiente, Universidade Federal de Alagoas, Maceió-AL, Brasil. ${ }^{2}$ Thiago Cavalcante Lins Silva, Programa de Pós-Graduação em Geografia, Universidade Federal de Alagoas, Maceió-AL, Brasil. ${ }^{3}$ Matheus de Araújo Soares, Instituto de Geografia, Desenvolvimento e Meio Ambiente, Universidade Federal de Alagoas, MaceióAL, Brasil.

${ }^{4} J o s e ́$ Ferreira dos Santos Júnior, Instituto de Geografia, Desenvolvimento e Meio Ambiente, Universidade Federal de Alagoas, Maceió-AL, Brasil.
} 
descontinuidades possibilitaram o desenvolvimento de uma grande diversidade de paisagens e arranjos geoambientais. Nesse contexto, a presença e interação dos elementos naturais abióticos: as águas, litologias, solos, relevo, minerais e jazigos fossilíferos, compreendem a geodiversidade. O conceito homônimo constitui uma abordagem integradora que busca agrupar os elementos abióticos da paisagem como conjunto, em resposta ao consolidado conceito de biodiversidade (STANLEY, 2001; JORGE; GUERRA, 2016).

A busca pela compreensão de como os elementos naturais abióticos e sua distribuição contribuem para o entendimento do desenvolvimento e funcionamento das mais variadas paisagens, constitui o objetivo das Geociências, em especial da Geografia Física, abordagem que busca compreender a organização espacial, dinâmica e estruturação dos sistemas naturais. Analisar os elementos naturais em suas interações possibilita a compreensão de como a distribuição dos conjuntos inorgânicos contribuem para a formação e manutenção dos complexos sistemas naturais, arranjos ambientais e sua interação com as diversas sociedades humanas (FUERTES-GUTIÉRREZ; FERNÁNDEZ-MARTINÉZ, 2010; GRAY, 2004; 2011; 2013).

Com a realização da ECO92, Conferência das Nações Unidas sobre o Meio Ambiente e o Desenvolvimento (CNUMAD) no Brasil, começou a ser discutida no País a necessidade de conceituar os elementos naturais, em consonância com o que existia no exterior (FERREIRA, 2014). Daí a realização de pesquisas e discussões científicas sobre a geodiversidade, enquanto elementos e conceito, e o patrimônio natural nacional. Um dos órgãos pioneiros na difusão desse tema foi o Serviço Geológico Nacional (CPRM), que realizou os estudos mais abrangentes sobre esse tema no País. Podem ser citados como exemplos dessa produção, o Mapa de Geodiversidade do Brasil, publicado em 2010, e os mapas estaduais de geodiversidade, a exemplo do Mapa de Geodiversidade do Estado de Alagoas, publicado em 2012 (CPRM, 2012).

As duas últimas décadas marcaram um período de avanços nos estudos sobre a geodiversidade no Brasil e no Nordeste. As pesquisas já realizadas têm mostrado a relevância que o tema ganhou junto às instituições de pesquisa, bem como, a emergência do tema no cenário científico nacional, havendo, inclusive, um aumento sucessivo na produção científica sobre a temática nos principais eventos acadêmicos da Geografia e Geologia (FREITAS et al., 2018; VON AHN et al., 2018). Isso implica dizer, no entanto, que se trata de uma temática ainda muito jovem e que deve ser amplamente discutida e difundida junto à Sociedade e as diversas esferas que compreendem a formação educacional da população brasileira. Trazendo novas contribuições para a apresentação e difusão dos conhecimentos sobre a Natureza, em parte, já abordados sob a ótica do conceito de biodiversidade, fortemente empregado no contexto científico da Educação Básica e Superior. 
Discutir, definir e redefinir o que compreende a geodiversidade, como ela deve ser estudada e deve ser conservada, para garantir sua manutenção para gerações futuras e contribuir para a manutenção da biodiversidade, deve ser o objetivo principal dos estudos sobre esse tema no Brasil (BORBA et al., 2013; FERREIRA, 2014). Novas pesquisas, discussões e aplicabilidades desse conceito, bem como, sua maior difusão junto à população, podem e devem ser incentivadas. Daí a importância dos estudos sobre o tema no Território Brasileiro, sejam em escalas regionais, estaduais ou locais.

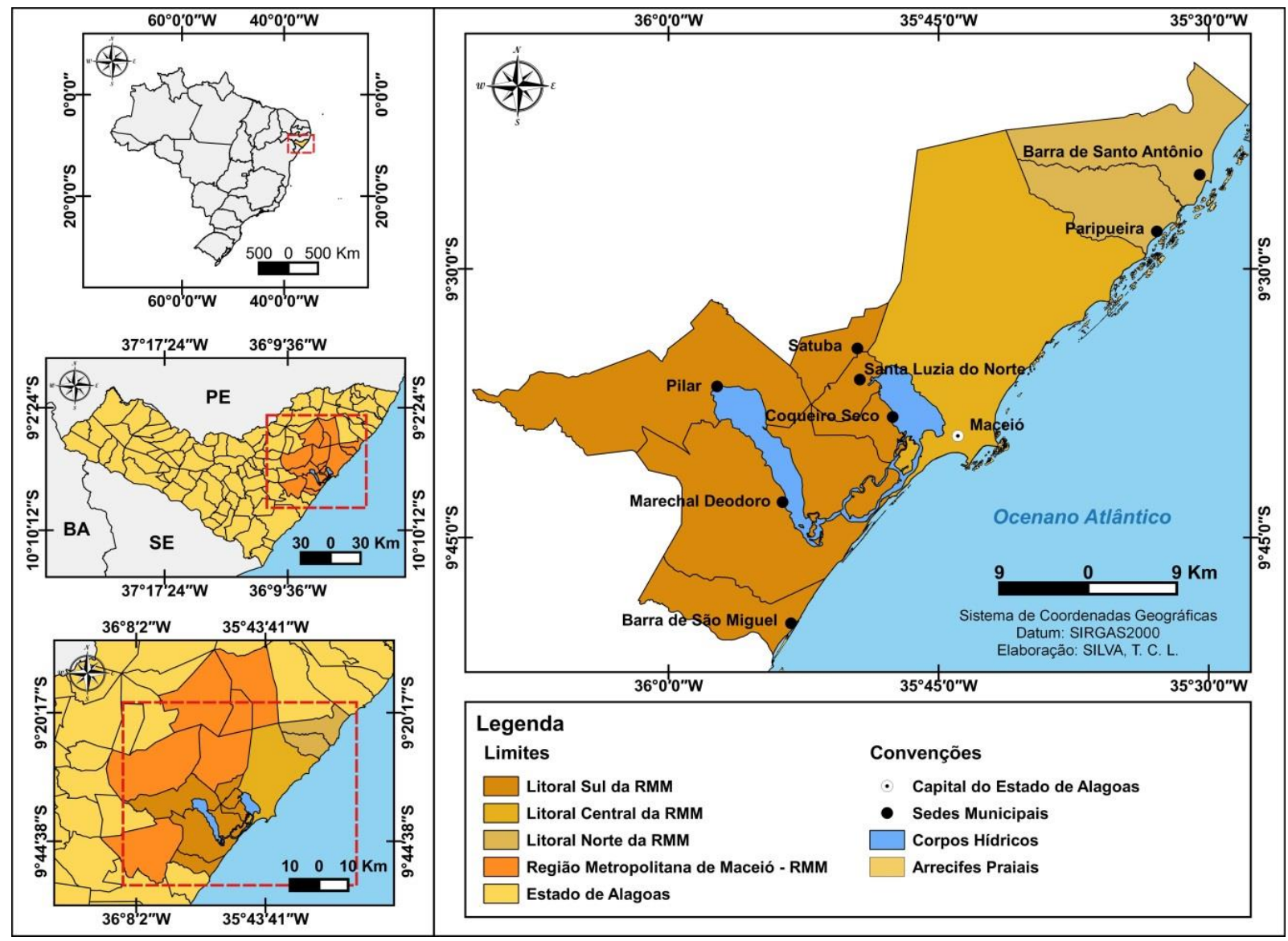

Figura 01. Mapa de localização da área de estudo. Fonte: Elaborado com base vetorial do IBGE (2015).

Revisitar os estudos já realizados sobre essa temática pode e deve representar um avanço no que concerne às pesquisas sobre a Geodiversidade Brasileira. Nesse sentido, com o intuito de caracterizar e detalhar a Geodiversidade da Região Metropolitana de Maceió - RMM (Fig. 01), trazendo novos métodos de análise, bem como, novas conceituações para elementos e conjuntos já descritos, é que se propõe o presente estudo. Buscando contribuir para uma maior difusão do tema no Estado de Alagoas, assim como, realizar um levantamento detalhado e avaliação do valor científico do Patrimônio Geológico de seu território, iniciando por sua porção litorânea, tendo como recorte os municípios sob influência das dinâmicas costeiras. Essa escolha se deu devido à presença, 
nessa região, de conjuntos naturais e ambientais extremamente importantes para a sua construção histórica e social, bem como, a riqueza de elementos e belezas naturais que apresenta.

\section{METODOLOGIA}

\subsection{Embasamento Teórico}

As análises sobre diversidade abiótica compreendem um desafio metodológico bastante instigante, dado o leque de possibilidades, testes e experimentações possíveis de utilização, uma vez que seus elementos e processos podem ser alvo de estudos em diversas áreas do conhecimento. Em um cenário de discussões sobre a diversidade abiótica, faz-se necessário a definição de algumas terminologias relacionadas à temática: Geodiversidade, Patrimônio Geológico e Geoconservação. Termos de significativa importância quando se busca compreender a temática, neste sentido, com o intuito de padronizar utilizada, ao longo do texto, as abordagens, foram utilizadas as definições expostas a seguir:

A Geodiversidade foi definida por Gray (2004 p.10) como a "diversidade geológica e geomorfológica, elementos que dão sustentação a biodiversidade. $O$ autor afirma que a geodiversidade corresponde "a variedade/diversidade natural de feições ou elementos geológicos, geomorfológicos e pedológicos, incluindo suas associações, propriedades, interpretações e sistemas". Brilha (2005), complementando a definição de Gray (2004), descreve a geodiversidade como sendo a variedade de ambientes, fenômenos, processos e elementos abióticos da Terra, no presente e no passado geológico. Segundo o autor, a interação desses elementos abióticos, entre si e com os seres vivos é que possibilitam a existência das mais variadas paisagens e conjuntos geoambientais da Terra.

O Patrimônio Geológico foi definido por Carcavilla et al. (2008) como sendo o conjunto de elementos geológicos que se destacam por seu valor científico, cultural ou educativo, o autor ainda discutiu a relação da geodiversidade com o termo em questão, afirmando que o estudo do mesmo, apesar de possuir relação com a geodiversidade, o Patrimônio Geológico é independente. Após isso, Brilha $(2016$; 2018) definiu o Patrimônio Geológico como sendo constituído pelos elementos excepcionais da geodiversidade, com elevados valores científicos que acabam á individualiza-los. O autor, com o intuito de refinar a classificação desses espaços, dividiu o Patrimônio Geológico em duas porções (Fig.02), os geossítios, quando determinado afloramento se localiza em campo; e os elementos do patrimônio geológico, quando o mesmo está extra campo, ambas as tipologias com presença de valores científicos. Brilha (2016) ainda classificou a feições sem valor científico como sendo Sítios de Geodiversidade, quando se encontram in situ e Elementos da Geodiversidade quando estão ex situ. 


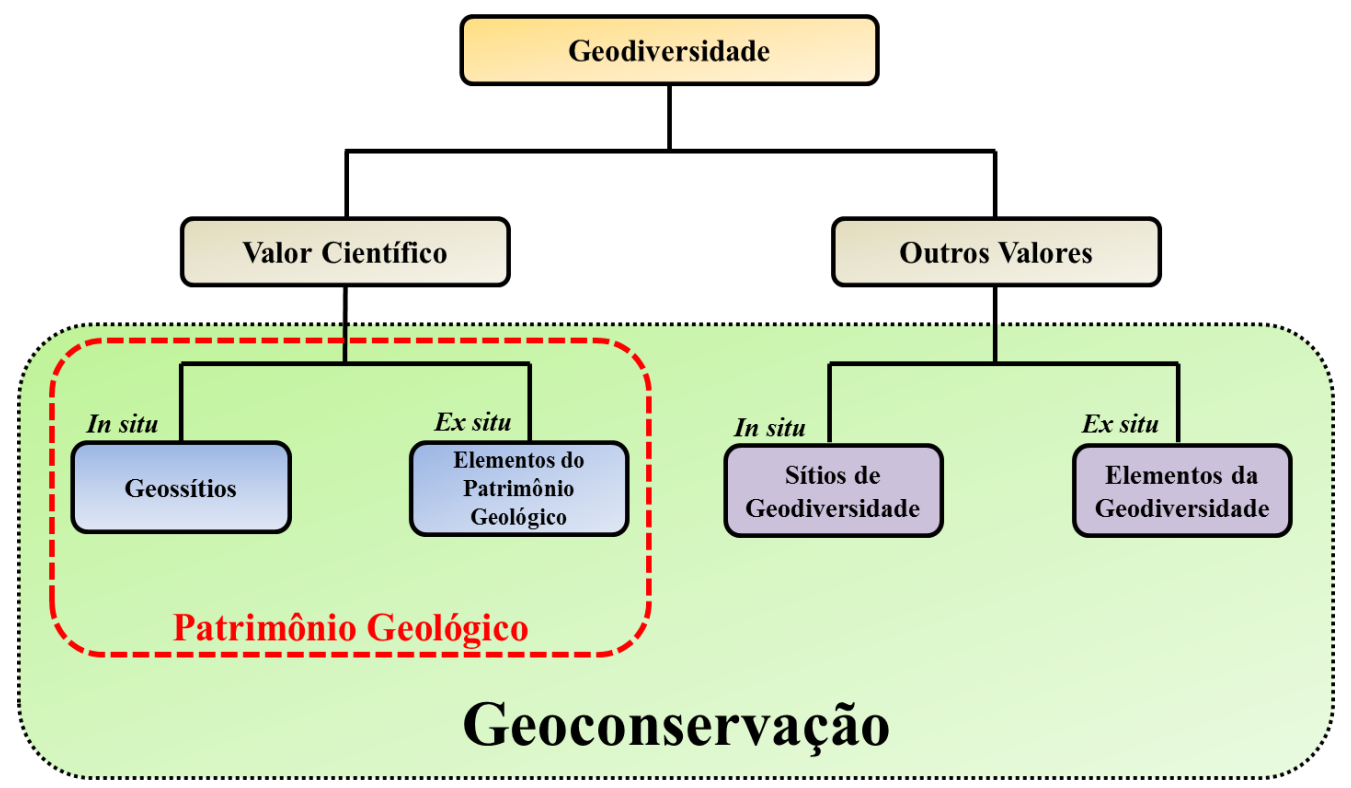

Figura 02. Modelo esquemático da divisão da diversidade natural. Fonte: Adaptado de Brilha (2018).

A Geoconservação pode ser definida, de acordo com Cumbe (2007), como o conjunto das atividades que possuem como objetivo a conservação, gestão e uso sustentável do Património Geológico e dos processos naturais a ele associados. Lima et al. (2010) ainda acrescentaram que a Geoconservação visa a popularização dos principais conceitos referentes às Geociências, como forma de criar uma consciência ambiental relativa à importância da preservação/conservação dos elementos excepcionais que compõe a Geodiversidade, ao mesmo tempo em que os mesmos se mantenham na paisagem. Para isso, de acordo com Lima (2008), o processo de efetivação da Geoconservação é segmentado em 6 etapas especificas de trabalho, nomeadamente: inventariação; avaliação quantitativa; classificação; conservação; valorização/divulgação e; monitoramento. Neste estudo optou-se por realizar apenas as duas primeiras etapas do processo de Geoconservação, a inventariação e avaliação quantitativa de áreas com expressiva geodiversidade, tendo em vista que os dois primeiros processos são bastante efetivos para uma avaliação inicial do patrimônio geológico loca.

A inventariação do patrimônio Geológico representa a etapa onde ocorre o levantamento, caracterização e espacialização de áreas potenciais da geodiversidade, fundamentando e dando prosseguimento para a realização das próximas etapas (PAULA; CASTRO, 2014; ARRUDA et al., 2017; GARCIA et al., 2018). De acordo com Lima (2008) no processo de inventário os estudiosos devem possuir um bom conhecimento sobre a área em estudo, além de objetivos bem definidos, evitando equívocos maiores. Para isso, faz-se necessário uma série de levantamentos preliminares 
sobre estudos prévios que envolvam a geodiversidade, mesmo que sem utilizarem essa terminologia como abordagem conceitual.

A avaliação quantitativa promove a quantificação de uma determinada área de excepcional geodiversidade, de acordo com seus riscos de degradação e valores (educativos, científicos e turísticos) (FRANÇA et al., 2016). A etapa de avaliação é processo primordial no contexto da geoconservação, pois avalia e seleciona as áreas mais relevantes para a conservação (BENTO; RODRIGUES, 2014). Daí a importância da Geografia, enquanto campo integrador de conhecimentos, abordagens e discussões sobre a paisagem, seus sistemas, conjuntos e correlações nos territórios e regiões. Possuindo abordagens teóricas, metodologias e discussões que podem ser utilizadas nas ações de caracterização, valoração, conservação e usos das áreas de expressiva geodiversidade.

\subsection{Procedimentos Metodológicos}

O conjunto metodológico proposto para este trabalho segmentou-se em 3 etapas específicas (Fig.03), a primeira foi a aquisição e processamento de dados cartográficos e bibliográficos, a segunda foram os trabalhos de campo na área de estudo, a terceira caracterizou-se pela inventariação e avaliação quantitativa do Patrimônio Geológico do Litoral da RMM e, por fim, a construção textual do presente trabalho.

Etapa 1
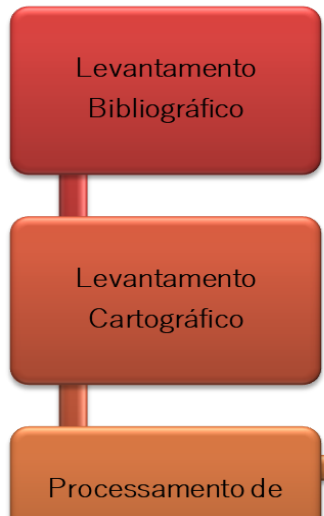

Dados
Etapa 2

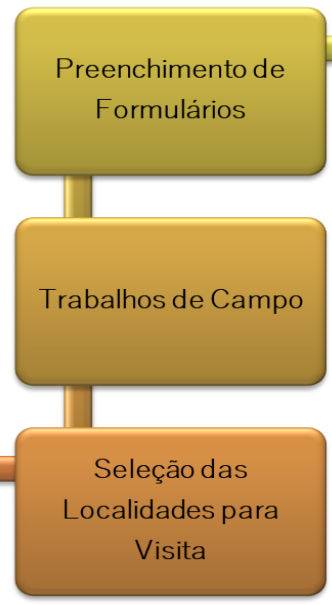

Etapa 3

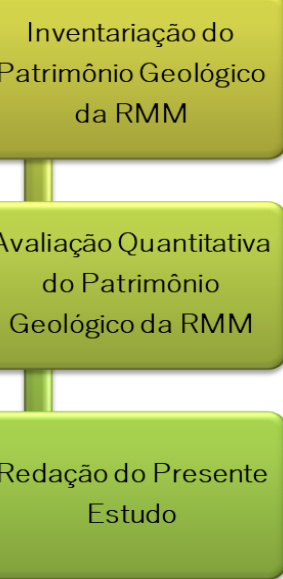

Figura 03. Fluxograma da metodologia do presente estudo. Fonte: Elaborado pelos autores (2019).

Na primeira etapa foram levantados dados cartográficos em bancos de dados de Domínio Público, onde foram selecionados os dados que melhor se enquadravam com a proposta do estudo e da escala de análise. Nesta etapa também foram realizados levantamentos detalhados sobre as bibliografias que tratam sobre a área. A partir desses dados foram selecionadas áreas e localidades 
amostrais, divididas em tipos de geossítios de acordo com os ambientes onde estão inseridos, com visitas a execução da etapa seguinte fundamentando os trabalhos de campo.

$\mathrm{Na}$ terceira etapa ocorreram os processos de inventário e avaliação quantitativa, onde realizou-se uma caracterização geral, com informações básicas sobre localização e acessibilidade, além de informações gerais sobre a diversidade abiótica das áreas, seguindo as proposições de Brilha (2016). Para a avaliação quantitativa dos Geossítios, que neste estudo só foram avaliados o valor científico e o risco de degradação, foi efetuada por intermédio de preenchimento de fichas e protocolos de avaliação, com critérios e subcritérios, com pontuações definidas (Fig. 04), assim como as propostas pelo mesmo autor supracitado.

Nisso, os levantamentos, descrições, caracterizações fisiográficas e á análises de valores e ameaças foram contempladas. Dando-se início a fase de elaboração do texto e descrição dos resultados obtidos, apresentando os principais aspectos da geodiversidade da Região. Tais resultados foram organizados na sequência apresentada no tópico seguinte.

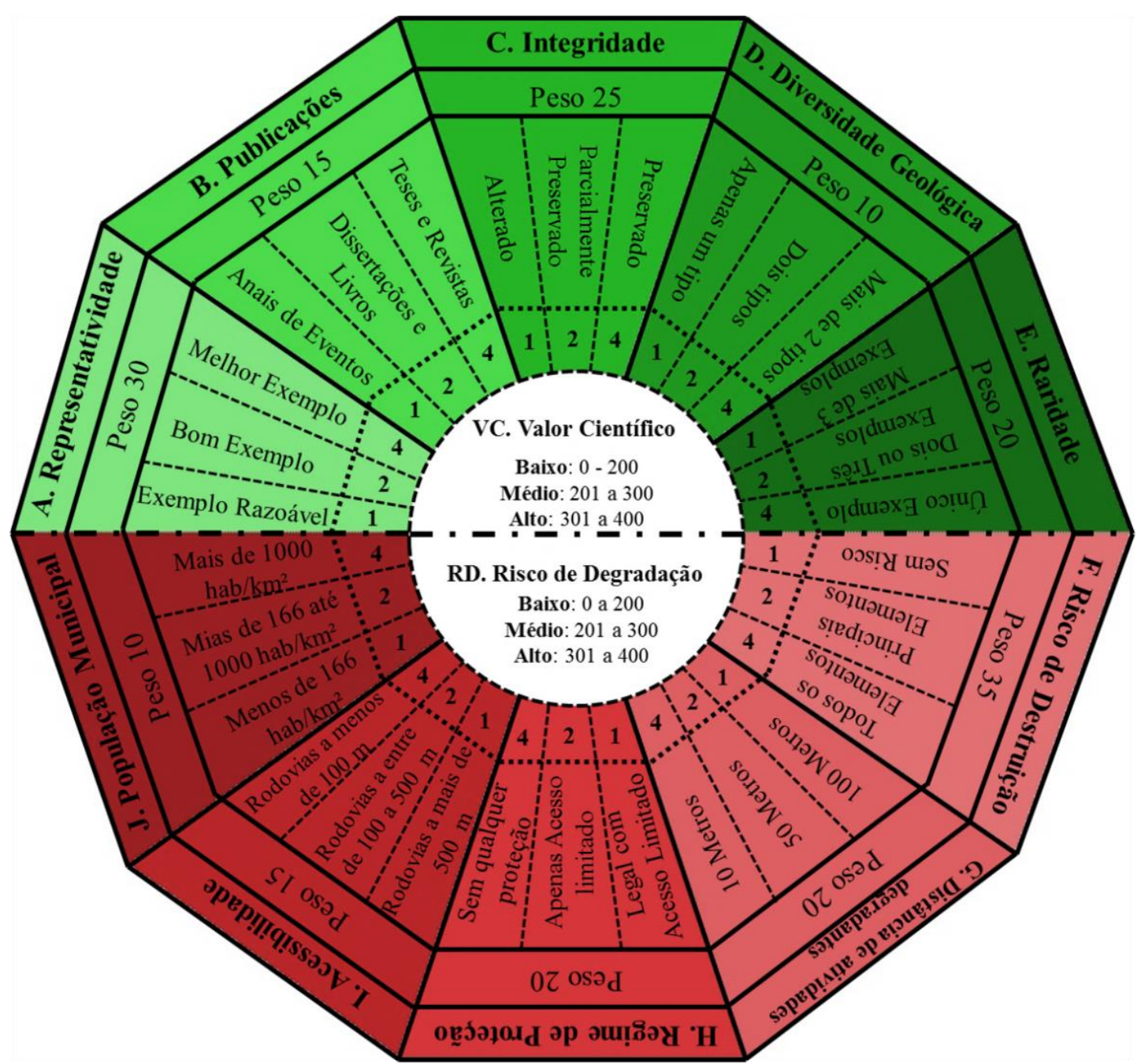

Figura 04. Critérios, pesos e subcritérios da avaliação quantitativa dos Valores Científicos e Riscos de Degradações dos Geossitios da RMM. Fonte: Adaptado de Bilha (2016). 


\section{RESULTADOS E DISCUSSÃO}

Com o intuito de descrever os resultados de forma mais sistemática será apresentado em um primeiro momento o processo de inventário do patrimônio geológico litoral da RMM, seguido pela avaliação quantitativa dos geossítios. Os resultados mostram que a geodiversidade presente na área é bastante expressiva e diversificada, compreendendo um mosaico de paisagens intimamente ligadas à dinâmica litorânea e estruturados sobre cordões arenosos, tabuleiros costeiros e terrenos alagadiços, bem como, as transições entre esses 3 ambientes distintos.

\subsection{Inventário do Patrimônio Geológico do Litoral da RMM}

Traçando uma contextualização geral do Geossítios do litoral da RMM (Fig.05), pode-se observar que os mesmos se distribuem de forma irregular ao longo do litoral. Ao todo foram inventariados 5 grupos de sítios geológicos, somando um total de 20 geossítios, estes estão melhor descritos a seguir, apresentadas por tipos de geossítios (fig. 05).

Setorizando o litoral da RMM em duas porções, a "parte baixa" e a "parte alta", observa-se que entre elas existem os Geossítios do tipo bordas planálticas (Falésias de Carro Quebrado - G01 e Paleofalésias Maceió - G08), estruturados em litologia sedimentar plio-plestocênica da Formação Barreiras, tabuleiros costeiros bordeados por encostas íngremes, entrecortados por vales fluviais estreitos. Sua porção mais à leste está representada por rampas de contato entre a planície e o planalto costeiros (Fig. 06). Os dois geossítios diferem entre si pela presença dos retrabalhamentos marinhos atual e pretérito, enquanto o G01 apresenta abrasão marinha, as falésias ativas, o G08 constitui antigas faixas de retrabalhamento da linha de costa, paleofalésias. A distribuição destas formas ocorre de modo desigual ao longo da RMM, ora próxima à linha de costa atual, ora distante alguns quilômetros (SILVA \& FERREIRA, 2017). Historicamente, primeiro a planície costeira e baixos cursos fluviais, e depois o topo dos tabuleiros, foram ocupadas por atividades ligadas ao cultivo de cana-de-açúcar, mas nos últimos anos, devido à proximidade com o mar e vistas panorâmicas, tem atraído empreendimentos imobiliários e turísticos.

No litoral há varias incidências de falésias e paleofalésias, entretanto, as formas mais representativas, com beleza cênica marcante, são as duas áreas que foram inventariadas, G08 e G01, por proporcionar vistas panorâmicas de seu entorno, neste contexto, apesar de representar um aspecto natural significativo há poucas menções em estudos científicos, localizados nas porções norte e central da área, respectivamente. 

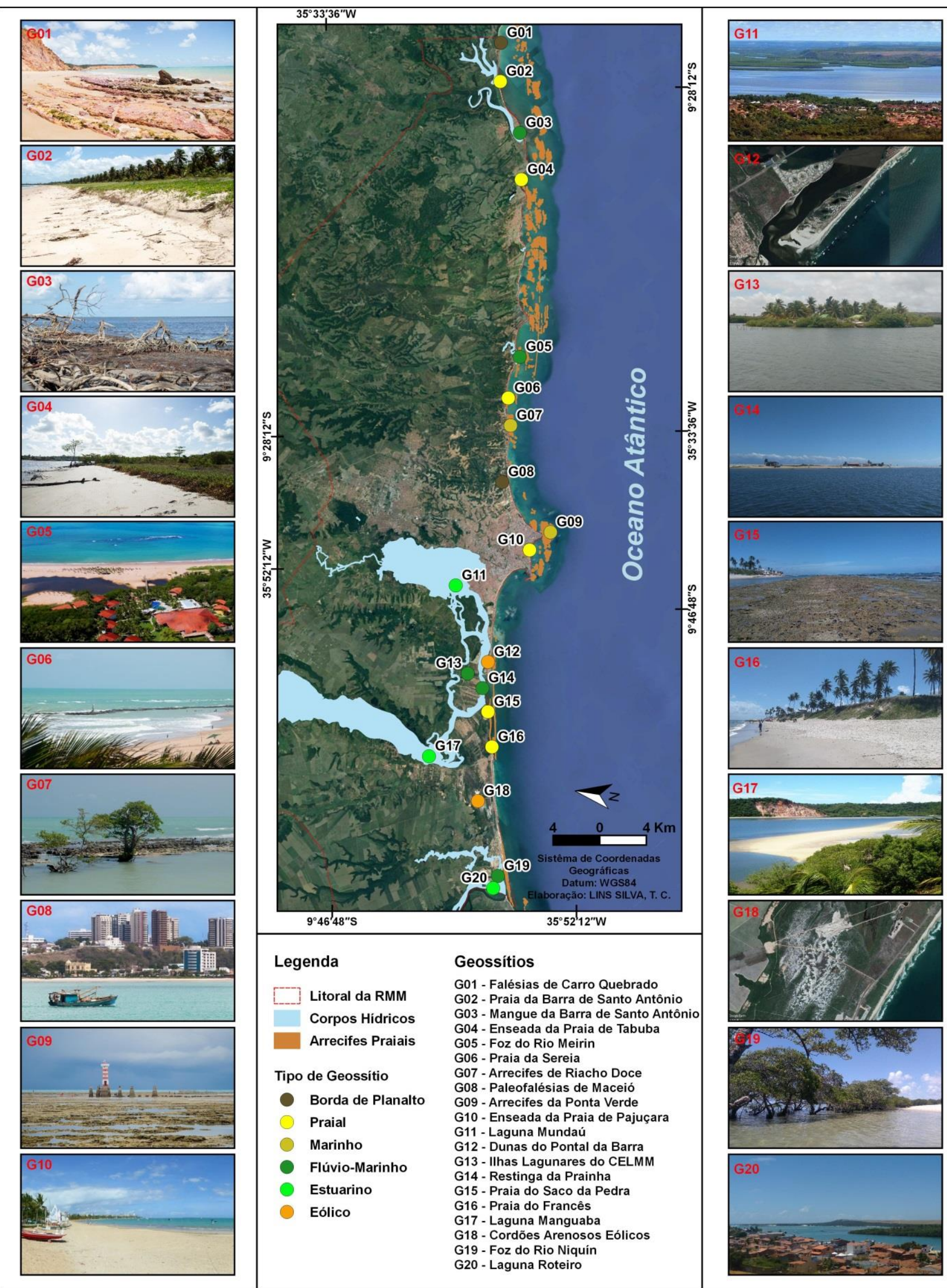

\section{Legenda}

Litoral da RMM
Corpos Hidricos
Arrecifes Praiais

Tipo de Geossítio

- Borda de Planalto

Praial

Marinho

- Flúvio-Marinho

- Estuarino

Eólico

\section{Geossítios}

G01 - Falésias de Carro Quebrado G02 - Praia da Barra de Santo Antônio G03 - Mangue da Barra de Santo Antônio G04 - Enseada da Praia de Tabuba G05 - Foz do Rio Meirin

G06 - Praia da Sereia

G07 - Arrecifes de Riacho Doce G08 - Paleofalésias de Maceió G09 - Arrecifes da Ponta Verde G10 - Enseada da Praia de Pajuçara G11 - Laguna Mundaú

G12 - Dunas do Pontal da Barra

G13 - Ilhas Lagunares do CELMM

G14 - Restinga da Prainha

G15 - Praia do Saco da Pedra

G16 - Praia do Francês

G17 - Laguna Manguaba

G18 - Cordőes Arenosos Eólicos

G19 - Foz do Rio Niquín

G20 - Laguna Roteiro
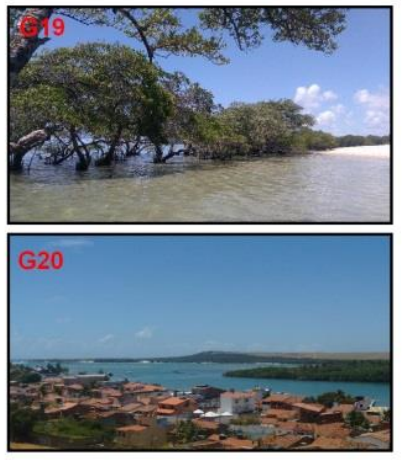

Figura 05 - Geossítios do litoral Região Metropolitana de Maceió. Fonte: Elaborado pelos autores com imagens de FERREIRA, 03/06/2019; 08/07/2019; 07/04/2019. 


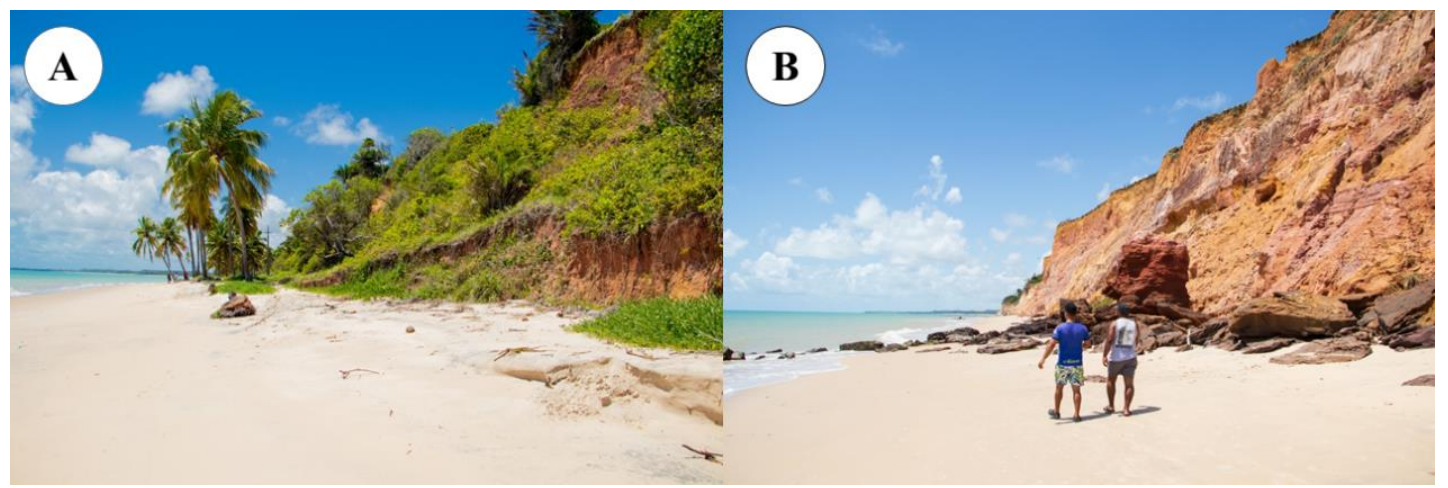

Figura 06 - Em detalhe duas porções de borda planáltica. A - Porção inativa ou fóssil e B - Porção ativa ou viva. Fonte: Acervo dos autores (30/03/2019).

Formando extensos tapetes de areias claras estão os geossítios praiais com variadas feições ao longo do Litoral, possuindo 7 localidades inventariadas (Geossítios G02, G04, G06, G010, G012 e G014), divididos em 3 subgrupos (Fig.07), as praias com arrecifes de arenito lineares, as praias com arrecifes de arenito em franja e as praias estruturadas em enseadas, com presença de arrecifes de maior extensão e mais distantes da costa, concentrando-se em desembocaduras fluviais e com maior dimensão.

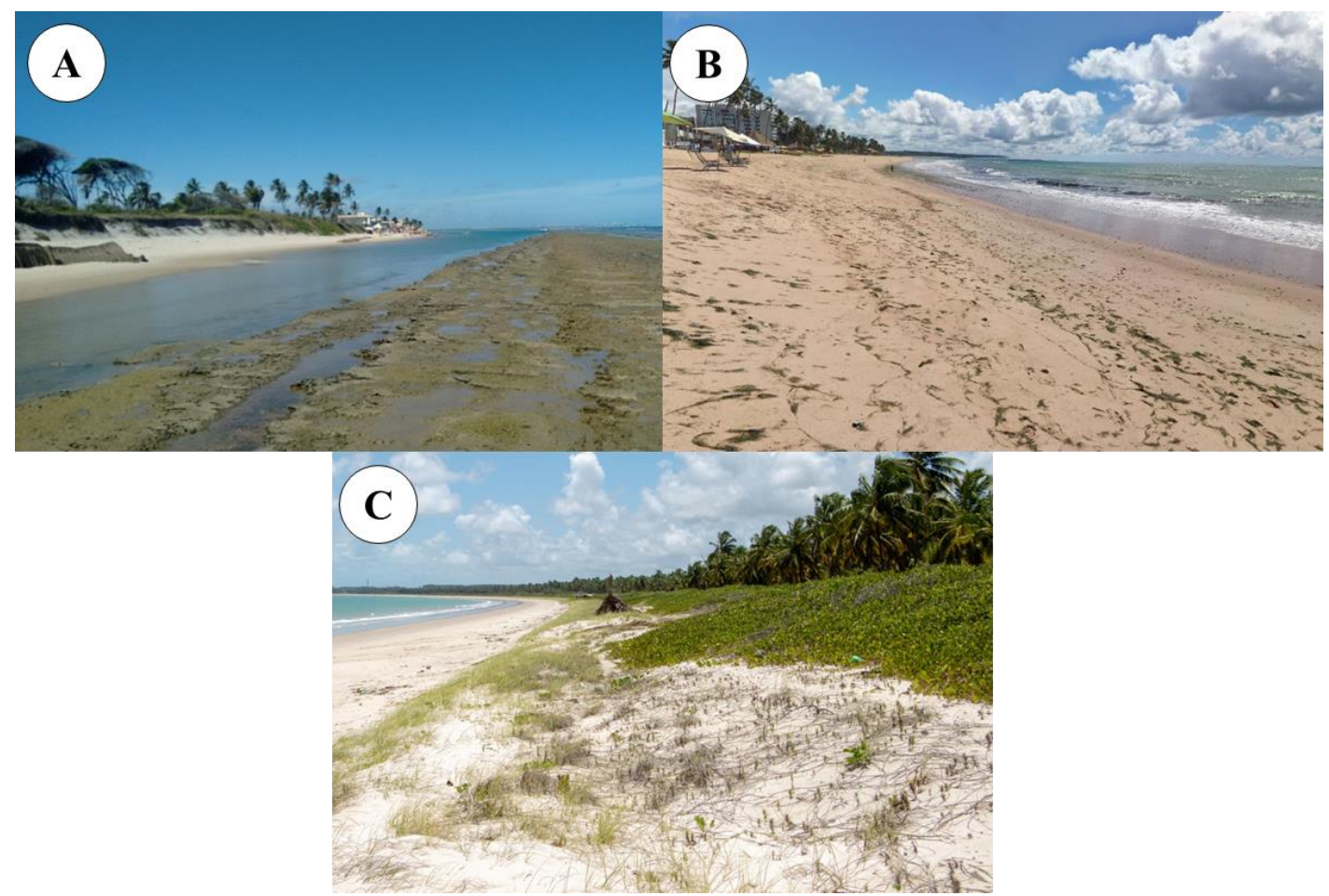

Figura 07 - Em detalhe três exemplos dos 3 subgupos. A - Praia do Saco da Pedra; B - Praia da Pajuçara e C - Praia da Barra de Santo Antônio. Fonte: Acervo dos autores (2019).

Protegidos por conjuntos de barreiras arrecifais, estão os geossítios G06, G015 e G016, que possuem sua morfologia praial condicionada pela presença de arrecifes com morfologia em linha, localizados a até 10 metros de distância da faixa de areia. Sua configuração morfológica, combinada 
ao fornecimento sedimentar regional faz com que estas feições tornem-se mais estáveis e resistentes a eventos erosivos intensos.

As praias controladas por estruturas arrecifais em franja possuem tendência à formação de pequenas enseadas limitadas por pontais arenosos, tornando as mesmas parcialmente resistentes às dinâmicas energéticas marinhas, quando seu trend de onda é paralelo ao direcionamento da franja arrecifal (LIMA, 2004). Na área é encontrada apenas uma feição com estas características que é a Enseada da Praia de Pajuçara (G10), amplamente difundida e conhecida.

As praias em enseadas controladas por extensas estruturas arrecifais e desembocaduras fluviais, são representadas pelos geossítios G02, praia da Barra de Santo Antônio, e G04 e praia da Tabuba, que se localizam em enseadas de média a grande proporção no contexto regional, condicionadas principalmente pela presença de arrecifes com até 200 metros de extensão, que conjugada a proximidade de áreas com fornecimento sedimentar ativo, permitindo, em parte, a formação de extensas faixas de areia e presença de dunas frontais com vegetação de restinga.

Em quase todos os geossítios, anteriormente descritos, devido à descontinuidade das barreiras arrecifais e interferências humanas, ao longo da faixa de areia, estão atuando processos erosivos intensos, principalmente em áreas ligadas a expansão urbana. Levando ao retrabalhamento a linha de costa e afetando não só a praia em geral, como também ecossistemas e a geodiversidade local (SILVA, 2001; SILVA, 2008; ARAÚJO et al., 2006). Ameaçando essa porção do Litoral Alagoano, a qual apresenta grande beleza cênica, com suas praias de águas quentes e cristalinas, presença de barreiras de arrecifes, configurando piscinas naturais.

Pontilhando as águas calmas e cristalinas do litoral da RMM, emergem os arrecifes de arenito (Fig.08), destacando-se na paisagem marinha rasa, possibilitando configurações praiais de expressiva beleza cênica. Sua distribuição, concentração e tamanhos são bastante irregulares, variando bastante entre as praias, entretanto, os maiores e mais diversificados são os Arrecifes da Ponta Verde e de Riacho Doce, em Maceió (G09 e G07), com morfologia linear e em franja, respectivamente. Esses corpos rochosos são compostos de arenito calcífero, localizando-se submersas e/ou parcialmente submersos em meio às águas rasas, parcialmente cobertos por algas e formações coralíneas.

Barbosa (1985), ao realizar datações em toda a porção costeira de Alagoas, datou os arrecifes da Região Metropolitana da Maceió, identificando idades em torno de $5200 \pm 230$ e $260 \pm$ 160 anos A.P., correspondentes ao último máximo transgressivo. Esses estudos sobre os arrecifes, apesar de datados, carecem de novos estudos, visto que o último estudo é da década de 1980, daí a necessidade de novos dados geocronológicos, além de detalhamento de suas características morfológicas no contexto local e regional. 


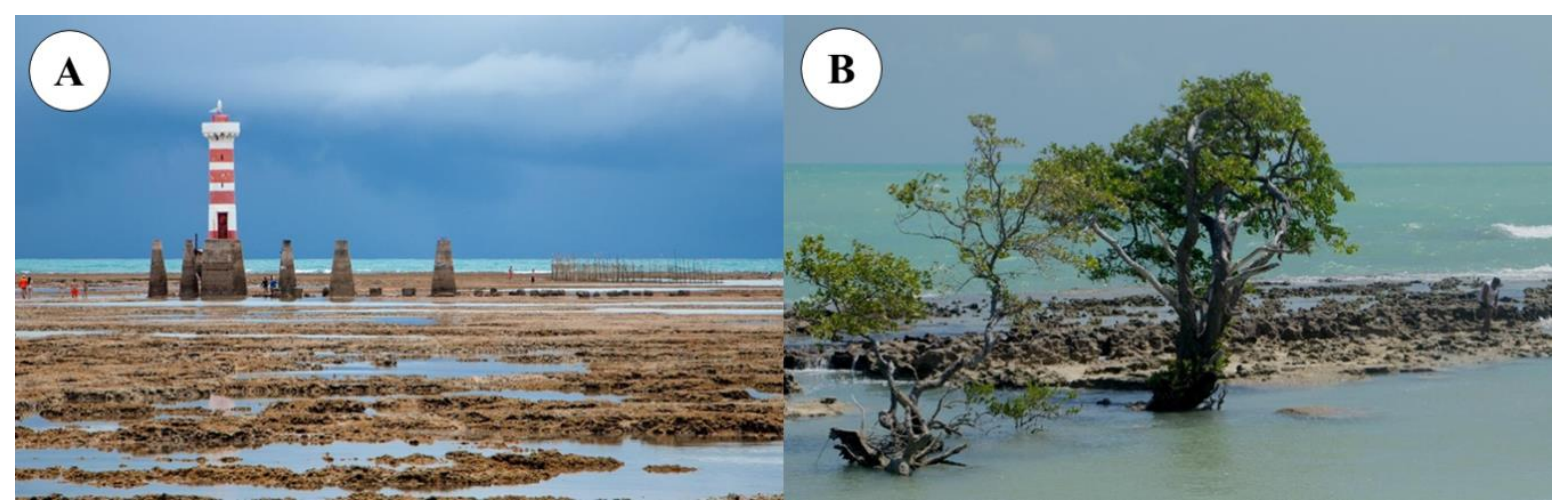

Figura 08. A - Arrecife em franja da Ponta Verde, porção central de Maceió. B - Arrecife em linha de Riacho Doce, litoral norte de Maceió. Fonte: Acervo dos autores (2018).

Os arrecifes da RMM podem ser encontrados em uma variedade de conjuntos, abrigando por vezes uma biota com variadas espécies, por este motivo, parte dos arrecifes da área encontram-se sob regime de proteção, do Instituto Chico Mendes de Conservação da Biodiversidade - ICMBIO, integrando a Área de Proteção Ambiental Costa dos Corais - APACC, criada em 1997, abrangendo os municípios pernambucanos de Tamandaré, Rio Formoso, Barreiros e São José da Coroa Grande. Já em Alagoas, engloba todo o litoral norte do Estado. A mesmo possui como foco a manutenção, preservação e uso sustentável dos arrecifes e da biota neles inserida. Essa área, ao longo do tempo, vem atraindo milhares de turistas todos os anos (STEINER, et al., 2006).

Ainda na Planície Costeira, estão os geossítios flúvio-marinhos, que possuem gênese e modelagem semelhantes, resultante do balanço morfodinâmico entre as dinâmicas marinhas e fluviais, bem como, suas morfologias transicionais. Estruturados sobre sedimentos arenosos e lamosos, estes modelados apresentam estrutura bastante vulnerável ás variações na dinâmica dos sistemas naturais. Esses geossítios podem ser divididos em 3 grupos, os geossítios sem estabilidade relacionada a cobertura vegetal (G14), os geossítios com cobertura vegetal parcialmente conservada (G15) e geossítios com cobertura vegetal densa (G03, G05 e G19).

A Restinga da Prainha (G14), um geossítio que tem sua morfodinâmica controlada pela deposição de sedimentos arenosos flúvio-marinhos inconsolidados, com cobertura vegetal rasteira e bordada por conjuntos de mangue, edificando barras arenosas regressivas, paralelas à linha de costa, regulando a entrada de águas marinhas no CELMM. De acordo com Barbosa (1985) e Vieira; Costa, (2009) a origem da Prainha está associada ao recuo do nível do mar após a penúltima transgressão marinha há aproximadamente 120.000 anos A. P., representando o único terraço pleistocênico do litoral sul da RMM. Sua configuração paisagística é bastante sensível a mudanças na dinâmica litorânea, oscilações de maré e deriva litorânea, estando constantemente sujeita às modificações morfológicas sazonais (LIMA, 1990; LIMA, 1998). A área faz parte da APA de Santa Rita, criada em 1985, a mesma é constantemente monitorada pelo Instituto do Meio Ambiente - 
IMA-AL. O que lhe confere proteção frente as agressões ambientais comuns no Litoral Alagoano. Os geossítios com cobertura parcialmente vegetada, possuem como principais fatores em sua modelagem à sobreposição de processos sedimentares (tanto marinhos como fluviais) combinada a presença de vegetação de mangue em seus depósitos lamosos, contribuindo para uma parcial resiliência a modificações na dinâmica energética dos sistemas de funcionamento. No entanto, dada a sua incipiente capacidade de resiliência, essas áreas são ainda bastante vulneráveis a degradação.

As Ilhas Lagunares do CELMM (G15), estruturam-se sobre sedimentos argilo-arenosos inconsolidados quaternários, de origem flúvio-marinha (MARQUES, 1987; LIMA, 1998). Configuram um conjunto de barras lamosas vegetadas e crôas, porções arenosas com vegetação incipiente, distribuídas próximas à desembocadura do CELM (fig.09). Possuem uma extensa área de manguezal, áreas de grande vínculo cultural e econômico com as comunidades locais, compostas por pescadores, coletores e catadores. Esta área é pouco estudada, ainda carente de dados sedimentológicos e geocronológicos mais precisos, necessitando assim de novos estudos. Este Geossítio encontra-se inserido em uma unidade de conservação, a APA de Santa Rita.

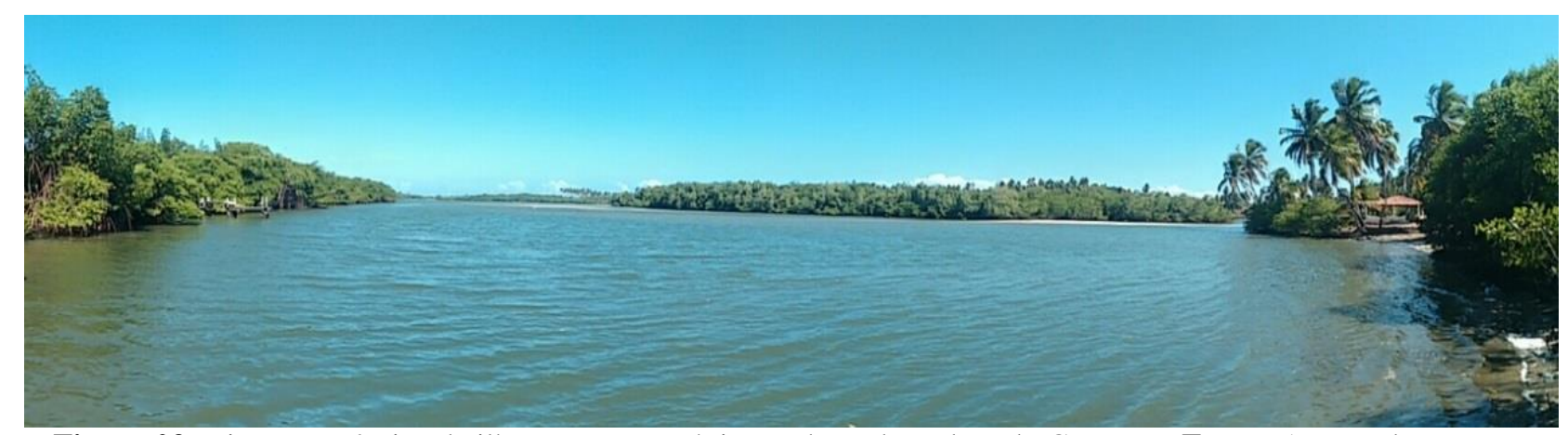

Figura 09. Vista panorâmica de ilhas Lagunar próxima a desembocadura do CELMM. Fonte: Acervo dos autores (2017).

Os geossítios com vegetação densa possuem sua modelagem influenciada pela presença de vegetação, especificamente as vegetações de mangue, que se estabelecem preferencialmente em depósitos lamosos, onde sua coesão influencia positivamente a estabilidade morfodinâmica, uma vez que sua coesão inviabiliza a retirada massiva de sedimentos pela hidrodinâmica. Configuração que se repete tanto nas desembocaduras fluviais do Rio Meirim (G05), como na foz do Rio Niquín (G19) quanto no pontal arenoso da Barra de Santo Antônio (G03). Vale mencionar que mediante as variações mais intensas, os depósitos lamosos e as vegetações nele instalados podem ser removidas, expondo estas áreas a períodos de instabilidade.

Formando espelhos d'água lagunares estão os geossítios das áreas estuarinas, resultantes de processos de escalonamentos de blocos provenientes da tectônica costeira cenozoica, dando origem 
a formação de superfícies rebaixadas amplas. Ao longo de períodos de calmaria tectônica recente e a variações positivas no nível relativo do mar no Quaternário, resultaram no retrabalhamento das encostas que bordeiam esses vales, ocasionando a formação amplos vales em "U" e extensas planícies de inundação, que preenchidos por águas marinhas e fluviais ocasionaram a formação de extensas “rias” de água salobra, as lagunas costeiras (GUERRA, 1966; AB'SABER; 1960, LIMA, 1998; DINIZ et al., 2016; SUGUIO, 2003). Os três geossítios da área compreendem estão inseridos no CELMM (G11 e G17) e o Complexo Estuarino Lagunar Roteiro - CELRO (G19).

Os CELMM e o CELRO possuem diversos estudos que versam sobre suas características fisiográficas e, mais recentemente, sobre sua Geodiversidade (LIMA, 1990; LIMA, 1998; SILVA \& FERREIRA, 2017; SILVA \& FERREIRA, 2018). Entre os maiores complexos estuarinos lagunares do Brasil, os CELMM e o CELRO, possuem íntima ligação com o processo de uso e ocupação das terras em seu entorno, uma vez que foram as primeiras porções de ocupação do Estado, tendo a sua geodiversidade como substrato. Ambos os complexos apresentam configurações fisiográficas marcantes, servindo de aporte para o desenvolvimento da biodiversidade local e, consequentemente, das comunidades tradicionais que a explora. Apesar de apresentar uma quantidade significativa de estudos e atividades protetivas os Complexos sofrem com processo de degradação ambiental, provenientes da falta de planejamento e fiscalização frente a atividades agrícolas, industriais, turísticas e residenciais.

Nos municípios de Maceió e Marechal Deodoro, estão os Geossitios eólicos (G12 e G18), as margens esquerda (G12) e direita (G18) do fechamento da desembocadura do CELMM, configurando-se morfologicamente por dunas e paleodunas vegetadas, com larguras e extensões variadas, formadas pelo entulhamento de sedimentação quaternária de origem flúvio-marinha, retrabalhada eolicamente. Apresentando uma série de morfologias dunas do tipo parabólica e Nebkha (G12), terraços e cordões arenosas retrabalhados em possíveis paleodunas (G18), com morfodinâmica constantemente multável.

\subsection{Avaliação Quantitativa do Patrimônio Geológico do Litoral da RMM}

$\mathrm{Na}$ avaliação quantitativa do Geossítios (Fig.09) foi possível ponderar os critérios de subcritérios do valor científico e do risco de degradação, obtendo pontuações variadas ao longo de toda a área. Analisando, de modo geral, as classificações das pontuações, foi possível observar que houve classificações diversas ao longo do litoral estudado, ocorrendo algumas localidades que se destacam, enquanto que a maioria apresentaram pontuações mais restritas. 


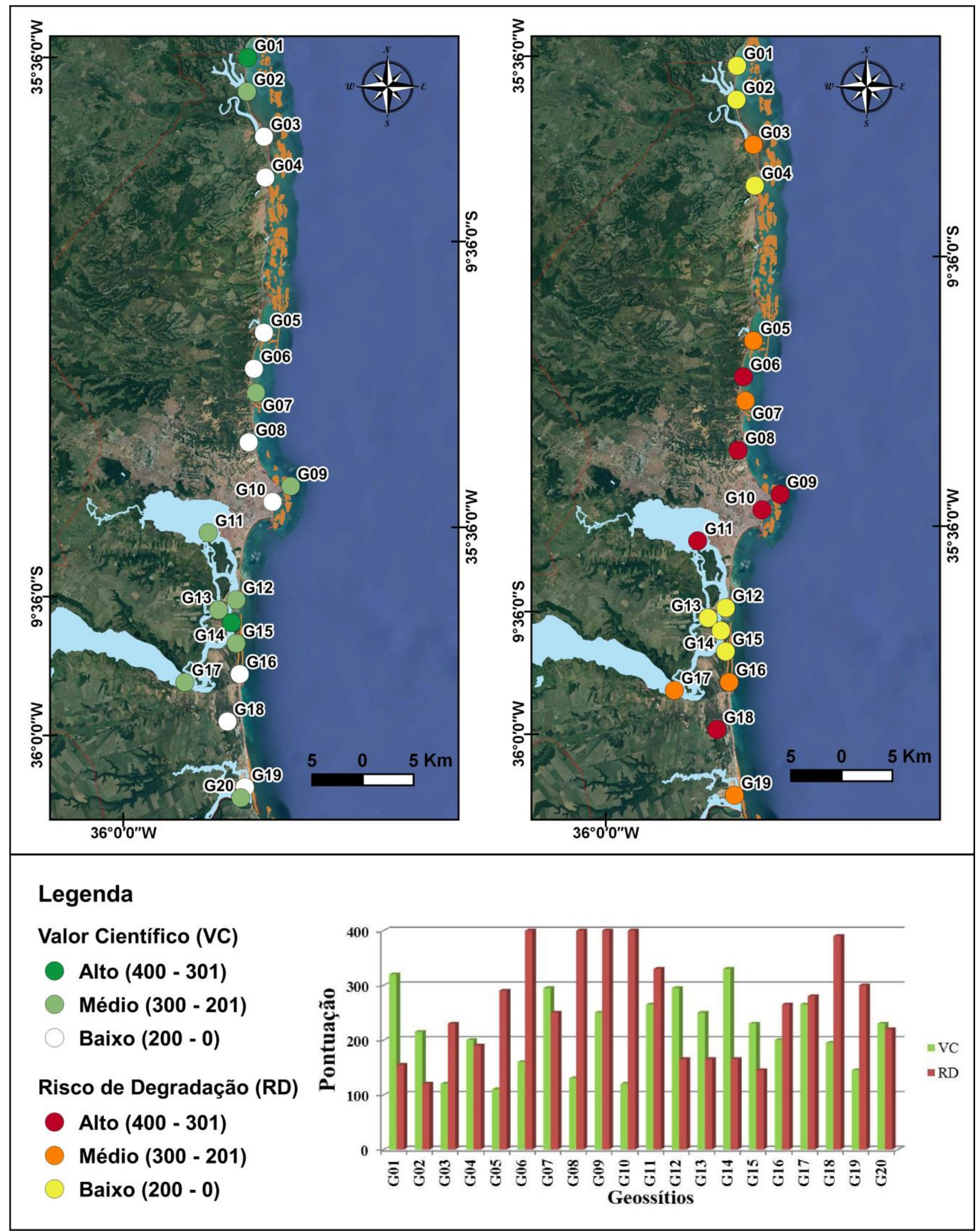

Figura 10. Valores Científicos e Riscos de Degradação do Patrimônio Geológico da RMM. Fonte: Elaborado pelos autores (2019).

Ainda quanto as análises quantitativas, a seguir estão apresentadas as cotações e pontuações (Quadro 01) calculadas no presente estudo: 


\begin{tabular}{|c|c|c|c|c|c|c|c|c|c|c|c|c|c|}
\hline & \multicolumn{5}{|c|}{ Critérios do Valor Científico (VC) } & \multicolumn{5}{|c|}{ Critério do Risco de Degradação (RD) } & \multicolumn{2}{|c|}{ Valores Finais } \\
\hline & & $\mathbf{A}$ & $\mathbf{B}$ & $\mathbf{C}$ & D & $\mathbf{E}$ & $\mathbf{F}$ & G & $\mathbf{H}$ & I & $\mathbf{J}$ & VC & RD \\
\hline \multirow{20}{*}{ 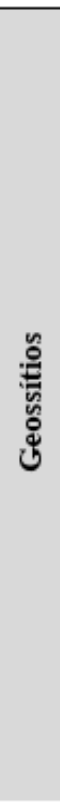 } & G01 & 4 & 0 & 4 & 2 & 4 & 2 & 1 & 2 & 1 & 1 & 320 & 155 \\
\hline & G02 & 2 & 1 & 4 & 2 & 1 & 1 & 1 & 2 & 1 & 1 & 215 & 120 \\
\hline & G03 & 1 & 0 & 2 & 2 & 1 & 2 & 4 & 2 & 2 & 1 & 120 & 230 \\
\hline & G04 & 2 & 0 & 4 & 2 & 1 & 2 & 2 & 2 & 2 & 1 & 200 & 190 \\
\hline & G05 & 1 & 0 & 2 & 1 & 1 & 2 & 4 & 2 & 4 & 4 & 110 & 290 \\
\hline & G06 & 2 & 1 & 1 & 2 & 2 & 4 & 4 & 4 & 4 & 4 & 160 & 400 \\
\hline & G07 & 4 & 1 & 4 & 2 & 2 & 2 & 2 & 2 & 4 & 4 & 295 & 250 \\
\hline & G08 & 2 & 1 & 1 & 1 & 1 & 4 & 4 & 4 & 4 & 4 & 130 & 400 \\
\hline & G09 & 4 & 2 & 2 & 1 & 2 & 4 & 4 & 4 & 4 & 4 & 250 & 400 \\
\hline & G10 & 1 & 1 & 1 & 1 & 2 & 4 & 4 & 4 & 4 & 4 & 120 & 400 \\
\hline & G11 & 4 & 4 & 1 & 2 & 2 & 2 & 4 & 4 & 4 & 4 & 265 & 330 \\
\hline & G12 & 4 & 1 & 4 & 2 & 2 & 2 & 1 & 1 & 1 & 4 & 295 & 165 \\
\hline & G13 & 2 & 2 & 4 & 2 & 2 & 2 & 1 & 1 & 1 & 4 & 250 & 165 \\
\hline & Gl4 & 4 & 4 & 2 & 2 & 4 & 2 & 1 & 1 & 1 & 4 & 330 & 165 \\
\hline & G15 & 2 & 4 & 2 & 2 & 2 & 2 & 1 & 1 & 1 & 2 & 230 & 145 \\
\hline & G16 & 2 & 2 & 2 & 2 & 2 & 2 & 4 & 4 & 1 & 2 & 200 & 265 \\
\hline & G17 & 4 & 4 & 1 & 2 & 2 & 2 & 2 & 4 & 4 & 3 & 265 & 280 \\
\hline & G18 & 4 & 0 & 1 & 1 & 2 & 4 & 4 & 4 & 4 & 3 & 195 & 390 \\
\hline & G19 & 1 & 4 & 1 & 1 & 1 & 2 & 4 & 4 & 4 & 1 & 145 & 300 \\
\hline & G20 & 2 & 4 & 2 & 2 & 2 & 2 & 2 & 2 & 4 & 1 & 230 & 220 \\
\hline
\end{tabular}

Quadro 01. Cotações e pontuações do Valor Científico (VC) e Risco de Degradação (RD) do Patrimônio Geológico da RMM. Fonte: Elaborado pelos autores (2019).

Com base nas análises realizadas, foi possível espacializar, descrever e avaliar as 20 áreas indicadas como representativas do Patrimônio Geológico da RMM, sendo geossítios distribuídos em 6 tipologias genético-funcionais relacionadas ao ambiente em que o mesmo se insere. A maior parte das áreas analisadas apresentaram valores científicos com tendência linear média entre valores médios a baixos (fig. 11), com praticamente 65\%, 13 Geossítios, apresentando valores próximos à média geral (216), enquanto outras apresentaram valores mais dispersos da tendência linear com praticamente 35\%, 7 Geossítios, neste sentido as localidades apresentam valores científicos classificados como predominantemente médios (Fig.12). Parte das localidades em análise apresentaram riscos de degradação bastante dispersos da tendência linear com 55\% (11 Geossítios) dispersos em relação à linha de tendência, resultando em percentuais semelhantes entre as classes, com Geossítios em classe baixa (35\%), média (35\%) e alta (30\%).

Os dados mostram que os Geossítios das Falésias de Carro Quebrado (G01) e a Restinga da Prainha (G14) apresentaram os mais altos Valores Científicos, dentre todas as áreas. Isso se dá por suas diversidades paisagísticas, distintas no contexto regional, bastante raras e com alto grau de conservação e exposição de suas características geológicas. Estejam elas expostas naturalmente em localidades acessíveis ou inacessíveis e protegidas por iniciativas de órgãos ambientais, com constantes visitas para monitoramento. Outro critério que colaborou com a classificação foi a oferta de produção bibliográfica, mostrando que a classificação obtida é coerente, mostrando o expressivo valor científico encontrado na área. 


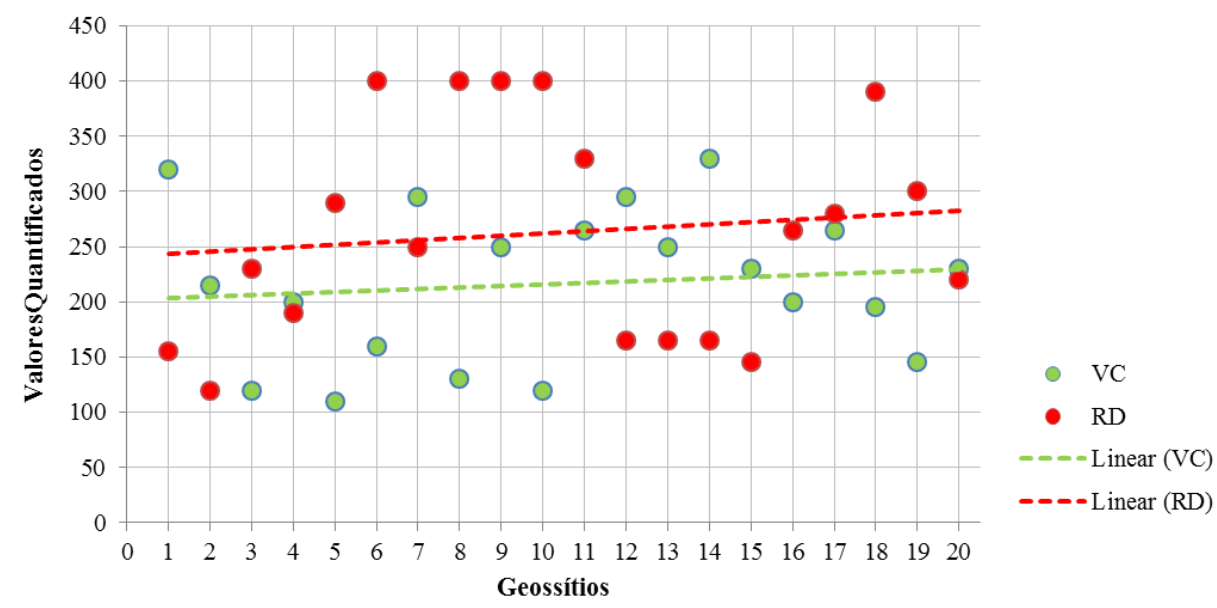

Figura 11. Gráfico de dispersão dos Valores Científicos (VC) e Risco de Degradação (RD) em tendência linear. Fonte: Elaborado pelos autores (2019)

Valor Científico por Classes

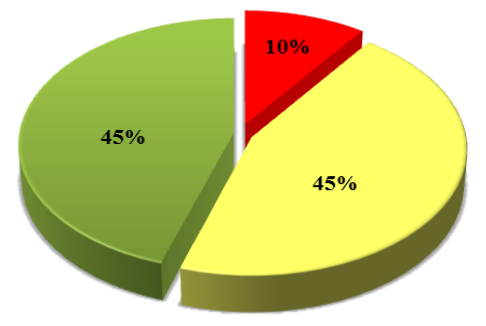

Risco de Degradação por Classes

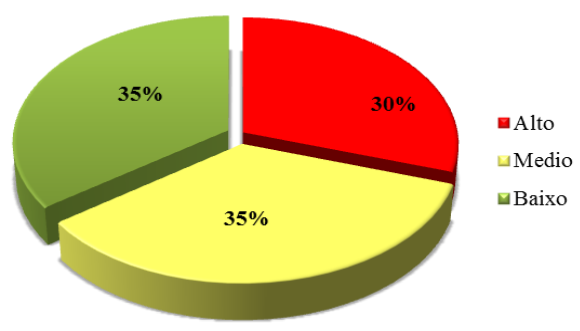

Figura 12. Gráfico com percentuais por classe de Valor Científico e Risco de Degradação. Fonte: Elaborado pelos autores (2019).

Os geossítios com valores científicos intermediários foram: Praia da Barra de Santo Antônio (G02), Arrecifes de Riacho Doce (G07), Arrecifes da Ponta Verde (G09), Laguna Mundaú (G11), Dunas do Pontal da Barra (G12), Ilhas Lagunares do CELMM (G13), Praia do Saco (G15), Laguna Manguaba (G17) e Laguna Roteiro (G20), com pontuações médias pela existência de localidades com características semelhantes, baixa raridade e diversidade de seus aspectos geoambientais no contexto regional, aliada a existência de poucos estudos que versem sobre suas características, dinâmicas e integridade ambiental. Esses fatores levaram a classificações médias, vale ressaltar que alguns Geossítios apresentaram características que fugiram do padrão mencionado em alguns aspectos, entretanto, convergindo na maioria das outras características comuns a classificação.

Os Geossítios Mangues da Barra de Santo Antônio (G03), Enseada de Tabuba (G04), Foz do Rio Meirin (G05), Praia da Sereia (G06), Paleofalésias de Maceió (G08), Enseada da Praia de Pajuçara (G10), Praia do Saco da Pedra (G15), Cordões arenosos eólicos (G18), Foz do Rio Niquín (G19), apresentam baixo valor científico. Isso se dá por que seus elementos apresentarem baixa 
raridade e se encontram com integridade afetada por atividades humanas intensas, motivando sua classificação como baixo valor científico. São áreas com níveis moderados e acentuados de degradação frente às atividades neles desenvolvidas, representando setores de interesse, mas sem grande expressividade no tocante ao valor científico.

Com relação ao Risco de Degradação (RD) foram encontrados em mais da metade dos geossítios valores baixos e médios, entretanto, apresentaram altos riscos de degradação os Geossítios: G06, G08, G09, G10, G11 e G18, principalmente por estarem muito próximos de núcleos urbanos e/ou frentes de expansão de atividades e empreendimentos turísticos, dotados de estruturas de acesso viário. Essas áreas correm risco de destruição dos seus principais aspectos, uma vez que se encontram sem qualquer regime de proteção, mais sistemático, frente a atividades irregulares, resultando em altos Riscos de Degradação.

Os Geossítios G03, G05, G07, G16, G17 e G19 obtiveram valores médios devido à ausência de regime de proteção, mais sistematizado, com planos específicos que visem salvaguardar as características abióticas destas áreas, que frente a difícil acessibilidade e a baixa densidade populacional em seu entorno resultaram em classificações de risco médio. Vale citar que alguns dos geossítios mencionados apresentam monitoramento ambiental, como é o caso da Praia do Saco da Pedra (G15) regidos pela RESEC homônima e dos Arrecifes de Riacho Doce (G07) gerenciados pela APACC, mas a alta densidade populacional em seu entorno e atividades irregulares contribuíram para suas classificações como média.

Os Geossítios que apresentaram baixo risco de degradação foram: G01, G02, G04, G12, G13, G14 e G15, os três primeiros foram classificados devido a sua difícil acessibilidade e distância de atividades potencialmente impactantes, que combinado a sua inserção em área de baixa densidade demográfica motivou sua classificação, já os demais obtiveram sua classificação por estarem inseridos na APA de Santa Rita e possuírem planos de manejo específicos, com controle de acesso e usos das terras dentro da área. Algumas dessas áreas são isoladas, com acessibilidade complicada, só possível ser acessadas por via aquática, o que contribui com sua classificação como de baixo risco de degradação.

\section{CONSIDERAÇÕES FINAIS}

Analisando-se os resultados obtidos foi possível concluir que o litoral da Região Metropolitana de Maceió apresenta um conjunto de geodiversidade diversificado, composto por um mosaico de feições, elementos e formas de apropriações, que o tornam passiveis de estratégias de conservação, visando, sobretudo, sua valoração e gestão. Neste contexto, o presente estudo realizou 
um processo de inventariação e avaliação quantitativa dos riscos ao patrimônio geológico da região. Constituindo uma iniciativa pioneira de debate sobre essa temática na RMM, entretanto, este estudo não representa um produto finalizado e concreto, e sim uma primeira aproximação de avaliação sistemática dos aspectos que compõe o Patrimônio Geológico da área.

Os resultados demonstraram a existência da relação entre o cotidiano da população e a geodiversidade local, seja ela apropriada ou não, com isso tornam-se necessárias estratégias e planos visando à valorização e conservação destes elementos, com enfoque maior naqueles com altos valores científicos, tendo em vista seu uso potencial para a pesquisa. Além do desenvolvimento de iniciativas que visem à proteção das áreas inseridas em contextos de pressão urbana, com elevados riscos de degradação. Estas ações resultariam em ganhos econômicos e sociais para a população inserida na região.

As descrições e avaliações, aqui efetuadas, podem e devem ser integradas a estratégias de planejamento e gestão do patrimônio natural pelo Poder Público, uma vez que além de fornecer um material descritivo simplificado, bastante útil na construção de painéis e placas explicativas, realiza também uma análise preliminar sobre áreas potenciais para conservação, em outras palavras realizando um diagnóstico ambiental prático, barato e que pode ser bastante útil, com níveis de precisão consideráveis nas análises. Nesse sentido pode-se afirmar que as descrições e análises aqui realizadas apresentam critérios positivos para sociedade, entretanto, o presente trabalho realizou apenas as duas primeiras fases do processo de conservação, a geoconservação, necessitando de prosseguimento para novas etapas de estudos e detalhamentos, visando melhor aplicabilidade de usos e proteção ambiental.

\section{REFERÊNCIAS}

AB'SABER, A. N. Contribuição à Geomorfologia do Estado do Maranhão. Notícia Geomorfológica, v.3, n.5, Campinas: 1960. p.35-45.

ARRUDA, K. E. C.; GARCIA, M. G. M.; DEL LAMA, E. M. Inventário e avaliação quantitativa do patrimônio geológico do Município de Caraguatatuba, São Paulo. Revista de Geociências, v. 36, n. 3, São Paulo: 2017. p. 447 - 462.

ARAÚJO, T. C. M. de; LIMA, R. C. de A.; SEOANE, J. C. S.; MANSO, V. do A. V. Erosão e progradação do litoral de Alagoas. In: MUEHE, D. C. E. H. Erosão e progradação do litoral brasileiro. Brasília: Ministério do Meio, 2006. p.57-73.

BARBOSA, L. M. Quaternário Costeiro no Estado de Alagoas: Influência das Variações do Nível do Mar. Dissertação de Mestrado apresentada ao programa de Pós-Graduação em Geologia, Universidade Federal do Ceará, 1981. 96p. 
BENTO, L. C. M.; RODRIGUES, S. C. Seleção de geossítios para uso turístico no parque estadual do Ibitipoca/MG (PEI): uma proposta a partir de metodologias de avaliação numérica. Investigaciones Geográficas, v. 2014, n. 85, Alicante: 2014. p. 33-46.

BORBA, A. W. D.; SOUZA, L. F. D.; MIZUSAKI, A. M. P.; ALMEIDA, D. D. P. M. D.; STUMPF, P. P. Inventário e avaliação quantitativa de geossítios: exemplo de aplicação ao patrimônio geológico do Município de Caçapava do Sul (RS, Brasil). Pesquisas em Geociências, v.40, n.3, Porto Alegre: 2013. p.275-294.

BRILHA, J. B. Património geológico e geoconservação: a conservação da natureza na sua vertente geológica. $1^{\circ}$ ed. Braga: Palimage, 2005. 90p.

BRILHA, J.; PEREIRA, D.; PEREIRA, P. Geodiversidade: valores e usos. $1^{\circ} \mathrm{ed}$. Braga: Universidade do Minho, 2008.16p.

BRILHA, J. Inventory and quantitative assessment of geosites and geodiversity sites: a review. Geoheritage, v. 8, n. 2, [S.I.]: 2016. p. 119-134.

BRILHA, J. Geoheritage: inventories and evaluation. In: REYNARD, E. \& BRILHA, J.. Geoheritage: Assessment, Protection, and Management. $1^{\circ} \mathrm{ed}$. Amsterdam: Elsevier, 2018. p. 69-85.

CARCAVILLA, L.; DURÁN, J. J.; LOPEZ-MARTÍNES, J. Geodiversidade: concepto y relación com el patrimônio geológico. Geo-Temas, v. 10, Las Palmas: 2008. p. 1299-1303.

CPRM - Companhia de Pesquisa de Recursos Minerais. Mapa geológico do estado de Alagoas. Recife, 2015.

CUMBE, A. N. F. O Património Geológico de Moçambique: Proposta de Metodologia de Inventariação, Caracterização e Avaliação. Dissertação de Mestrado apresentada ao Programa de Pós-Graduação em Património Geológico da Universidade do Minho, Braga, 2007. 132p.

DINIZ, M. T.M.; VASCONCELOS, F. P.; OLIVEIRA, G. P.; MEDEIROS, D. B. S. Geografia costeira do nordeste: bases naturais e tipos de uso. $1^{\circ} \mathrm{ed}$. Curitiba: EDITORA CRV, 2016. 120p.

FUERTES-GUTIÉRREZ, I.; FERNÁNDEZ-MARTINÉZ, E. Geosites inventory in the Leon Province (Northwestern Spain): a tool to introduce geoheritage into regional environmental management. Geoheritage, v. 2, n. 1-2, [s.i.]: 2010. p. 57-75.

FERREIRA, B. Geodiversidade do estado de Pernambuco. Tese de doutorado apresentada ao programa de pós-graduação em geociências da Universidade Federal de Pernambuco - UFPE, Recife, 2014. 243p.

FRANÇA, L. F. de O.; MARIANO, G.; HORA, B. R. C. Avaliação quantitativa de sítios de geodiversidade utilizando a técnica de análise de agrupamentos: estudo de caso. Caderno de Geografia, v. 26, n. 45, Minas Gerais: 2016. p. 27-54.

FREITAS, L. C. B.; VERÍSSIMO, C. U. V., LIMA BRANDÃO, R., DANTAS, M. E., \& SHINZATO, E. Geodiversidade conceitos, aplicações e estado da arte no Brasil: uma aplicação ao Geopark Araripe. Estudos Geológicos, v. 28, n.1, Recife: 2018. p. 86-103. 
GARCIA, M. G. M.; BRILHA, J.; LIMA, F. F.; VARGAS, J. C.; PÉREZ-AGUILAR, A.; ALVES, A.; FIERZ, M. D. S. M. The Inventory of Geological Heritage of the State of São Paulo, Brazil: Methodological Basis, Results and Perspectives. Geoheritage, v.10, n.2, [s.i.]: 2018. p.239-258.

GRAY, M. Geodiversity: valuing and conserving abiotic nature. $1^{\circ}$ ed. Londres: John Wiley \& Sons, 2004. 130p.

Other nature: geodiversity and geosystem services. Environmental Conservation, v. 38, n. 3, Cambridge: 2011. p. 271-274.

Geodiversity: valuing and conserving abiotic nature. $2^{\circ}$ ed. Chichester: Wiley Blackwell, 2013.

GUERRA, A. T. Vales Submersos da Amazônia. Revista Brasileira de Geografia, v.24, n.3, Rio de Janeiro: 1966. p.327-492.

IBGE - Instituto Brasileiros de Geografía e Estatística. Malha municipal digital do Estado de Alagoas, $2015 . \quad$ Disponível em: ftp://geoftp.ibge.gov.br/organizacao_do_territorio/malhas_territoriais/malhas_municipais/municipio _2015/UFs/AL/. Acesso: 05 de set. 2019.

JORGE, M. C. O.; GUERRA, A. J. T. Geodiversidade, geoturismo e geoconservação: conceitos, teorias e métodos. Espaço Aberto, v. 6, n. 1, Rio de Janeiro: 2016. p. 151-174.

LIMA, F. F. Proposta metodológica para a inventariação do Patrimônio Geológico Brasileiro. Dissertação de Mestrado apresentada ao Programa de Pós-Graduação em Patrimônio Geológico da Universidade do Minho, Braga, 2008. 110p.

LIMA, F. F., BRILHA, J.B., SALAMUNI, E. Inventorying geological heritage in large territories: a methodological proposal applied to Brazil. Geoheritage, vol. 2, [s.i.]: 2010. p. 91-99.

LIMA, I. F. Maceió, a cidade restinga: contribuição ao estudo geomorfológico do litoral alagoano. $2^{\circ}$ ed. Maceió: EDUFAL, 1990. 230p.

LIMA, R. C. A. Estudo sedimentológico e geoambiental no sistema lagunar Mundaú Alagoas. Dissertação de Mestrado apresentada ao Programa de Pós-graduação em Geociência da Universidade Federal de Pernambuco, Recife, 1998. 150p.

LIMA, R. C. A. Evolução da Linha de Costa a Médio e Curto Prazo Associada ao Grau de Desenvolvimento Urbano e aos Aspectos Geoambientais na Planície Costeira de MaceióAlagoas. Tese de Doutorado apresentada ao programa de pós-graduação em Geociências da Universidade Federal de Pernambuco, 2004. 240p.

MARQUES, R. C. Geomorfologia e evolução da região costeira do complexo estuarino lagunar Mundaú Manguaba. Dissertação de Mestrado apresentada ao programa de pós-graduação em Geomorfologia da Universidade Federal do Rio de Janeiro, 1987. 90p. 
PAULA, S. F. \& CASTRO, P. T. A. Protocolo de avaliação e inventariação de lugares de interesse geológico e mineiro. SeTur/SBE. Pesquisas em Turismo e Paisagens Cársticas, v.7, n.1, Ouro Preto: 2014. p.19-27.

SILVA, A. P. L. Estudos geomorfológico e sedimentológico do sistema estuarino lagunar do roteiro - Alagoas. Dissertação de Mestrado apresentada ao Programa de Pós-graduação em Geociência da Universidade Federal de Pernambuco, Recife, 2001. 153p.

SILVA, A. P. L. Diagnóstico Geoquimico e Geocronologia do Sistema Estuarino Lagunar do Roteiro - Alagoas. Tese de Doutorado apresentada ao programa de pós-graduação em Geociências da Universidade Federal de Pernambuco, 2008. 230p.

SILVA, T. C. L. \& FERREIRA, B. Levantamento dos principais aspectos da geodiversidade do município de Maceió, estado de Alagoas, nordeste do Brasil. In: PEREZ-FILHO, A. P.. Os Desafios da Geografia Física na Fronteira do Conhecimento: XVII SBGFA e I CNGF, Campinas: Instituto de Geociências da UNICAMP, 2017.

SILVA, T. C. L. \& FERREIRA, B. Levantamento da geodiversidade do Complexo Estuarino Lagunar Mundaú Manguaba, Região Metropolitana de Maceió, Estado de Alagoas, Nordeste do Brasil. Anais do XII Simpósio Nacional de Geomorfologia, 2018. Disponível em:< http://www.sinageo.org.br/2018/trabalhos/5/5-295-2179.html.> Acesso em: 05 de set. 2019.

STANLEY, M. Welcome to the $21^{\circ}$ century. Geodiversity Update, v.1, Sidney: 2001. p. 1-8.

STEINER, A. Q., ElOY, C. C., AMARAL, J. R. B. C., AMARAL, F. M. D., \& SASSI, R. O turismo em áreas de recifes de coral: considerações acerca da Área de Proteção Ambiental Costa dos Corais (Estados de Pernambuco e Alagoas). OLAM-Ciência e Tecnologia, v. 6, n. 2, Rio Claro: 2006. p. 281-296.

SUGUIO, K. Geologia Sedimentar. $2^{\circ}$ ed. São Paulo: Editora Edgard Blücher, 2003. 363p.

VIEIRA, J. L.; COSTA, J. A. A Dinâmica Natural Da Prainha E Do Seu Entorno, Marechal Deodoro-AL: Uma Análise Geomorfológica E Socioambiental. Revista Para Onde!?, v. 4, n.2, Porto Alegre: 2010. p.3- 12.

VON AHN, M. M.; NASCIMENTO, M. A. L.; SIMON, A. L. H. Panorama da produção científica sobre os 5 G's nas geociências (geologia e geografia física) no período de 2004 e 2017. Anais do XII Simpósio Nacional de Geomorfologia, 2018. Disponível em:< http://www.sinageo.org.br/2018/trabalhos/5/5-307-491.html>. Acesso em: 05 de set. 2019.

\section{AGRADECIMENTOS}

Os autores do presente estudo gostariam de agradecer as instituições e programas que contribuíram para sua realização: a Universidade Federal de Alagoas (UFAL) e seu Programa de Bolsa Institucional de Iniciação Científica (PIBIC); ao Instituto de Geografia, Desenvolvimento e 
Meio Ambiente (IGDEMA); ao Programa de Pós-Graduação em Geografia (PPGG/UFAL); e ao Laboratório de Geologia do IGDEMA (LABGEO).

Recebido em: 10/09/2019.

Aceito para publicação em: 17/12/2019. 